\title{
Euvres-frontières de la littérature québécoise des années 1930-1940
}

\author{
David Décarie \\ Université de Moncton \\ Pierre Rajotte \\ Université de Sherbrooke
}

La littérature québécoise des années 1930 et 1940 est marquée par de nombreux bouleversements. Tout en cherchant à se moderniser et à s'autonomiser, elle donne lieu à diverses formes d'expérimentation textuelle. À l'ombre des œuvres phares et des « classiques » (Chartier, 2000) de la période apparaissent alors des œuvres-frontières qui contournent les catégories génériques traditionnelles: romans sans intrigue mettant en scène des spéculations philosophiques, contes ou reportages flirtant avec l'autofiction, textes commémoratifs issus de collages de sources inattendues, ouvrages mixtes dont il est difficile de situer le genre, autant de cas atypiques où se négocie un équilibre inédit entre la prose d'idées et des formes variées d'usage de la fiction. Si l'histoire littéraire s'est particulièrement intéressée à certaines de ces œuvres hybrides (ex. le «roman-poème » Menaud, maître-draveur de Félix-Antoine Savard), il faut bien admettre qu'elle n'y voyait bien souvent que des épiphénomènes. Or, il y a tout lieu de parler d'une tendance importante qui illustre à quel point l'époque cherche à se renouveler. Le présent numéro de la revue @nalyses vise à proposer une réflexion sur cette production ${ }^{1}$.

\footnotetext{
${ }^{1}$ Le présent numéro fait suite à deux journées d'étude organisées par Marie-Frédérique Desbiens, Mylène Bédard et Karine Cellard que nous remercions. La première s'est tenue le 23 octobre 2015 à l'Université Laval et la seconde le 10 mai 2016 à l'UQAM. Ces rencontres visaient à mieux comprendre la spécificité et l'intérêt d'une production littéraire hybride au Québec.
} 
www.revue-analyses.org, vol. 15, nº1, printemps-été 2020, p. 1-4.

Paradoxalement, des lignes de force se dessinent dans la nébuleuse des œuvres-frontières puisque des formes peu pratiquées jusqu'alors, telle la maxime, les traversent. Les œuvresfrontières se rejoignent également aux confins des frontières qu'elles mettent à mal: celles de l'autobiographie et la fiction, mais également celle des genres (du récit bref, du roman et de l'essai). Les trois premiers textes proposent ainsi de rassembler et de lire conjointement plusieurs de ces œuvres protéiformes afin de mieux cerner leur signification. Denis Saint-Jacques prospecte du côté des récits brefs au genre incertain (s'agit-il de contes, de nouvelles, de récits, voire de romans?) dont la portée autobiographique ou mémorielle présente des contours indécis et dans lesquels la frontière entre fiction et réalité s'avère bien souvent poreuse. Là où l'on s'attendrait à ce que l'une exclue l'autre, on peut, a contrario, se demander si la valeur de ces œuvres littéraires n'est pas largement tributaire de leur façon de conjoindre l'authenticité des faits rapportés et une vérité de la forme. L'autonomie du champ semble suppléer à une instabilité référentielle. Est-ce à dire qu'en littérature, la vérité se démontre moins par une documentation appuyée que par l'esthétisme et l'autorité de l'écrivain? Étudiant neuf œuvres-frontières des années 1930 et 1940, David Décarie et Marie-Frédérique Desbiens décrivent un nouveau type de roman qu'ils proposent de nommer «romans-essais». S'appuyant sur la réception de l'époque, ils repèrent les nombreuses caractéristiques communes (thématiques et formelles) de ces œuvres, tant dans leurs versants romanesques (hybridité, autoréflexivité, caractère autobiographique et dissolution de l'intrigue) que dans leurs versants essayistiques (fragmentation; caractère négatif; mise à distance des idées). Comme plusieurs de ces caractéristiques sont également celles de l'essai littéraire, ils se demandent si le roman-essai ne constituerait pas l'un des précurseurs de ce genre. Michel Lacroix se penche sur l'écriture de maximes qui traverse certaines œuvres-frontières des années 1940. Issu d'une réflexion sur la trilogie d'Anatole Laplante de François Hertel, son texte aborde successivement les « romans- 
essais » de Pierre Baillargeon et de Jean Simard puis les œuvres inclassables de tendances autobiographiques de Fernand Rinfret, de Marylène et de Thérèse Tardif. La posture moraliste que l'on retrouve dans ce corpus permet de mieux comprendre les enjeux esthétiques et idéologiques de l'écriture des maximes. Cette dernière met également en lumière les transformations significatives du roman-essai qui n'est pas étranger au dynamisme à l'époque du processus d'autonomisation de la littérature québécoise.

Mais les œuvres-frontières demandent en même temps à être lues dans leur singularité et les deux textes suivants du présent numéro cherchent à mieux comprendre des œuvres aussi riches qu'énigmatiques. Lucie Robert révèle une forme de paradoxe au sujet de La Merveilleuse aventure de Jacques Cartier (1934) de Marius Barbeau. Bien qu'on célèbre en 1934 le 400 anniversaire de l'arrivée de Jacques Cartier à Gaspé, l'ouvrage de Barbeau est pratiquement passé inaperçu au moment de sa publication. La forme et les idées de cette œuvre-frontière, qui témoignent à la fois de l'audace et de l'imagination de l'auteur, y sont sans doute pour quelque chose. En effet, loin de s'en tenir à une stricte dimension historiographique, Barbeau propose un montage de citations et d'idées qui comporte de multiples traits singuliers pour l'époque. Ce qu'on pourrait considérer comme un fantaisiste opuscule apparait alors comme un ouvrage dans lequel se déploie une lecture originale de l'histoire proposant une contre-lecture à La Découverte du Canada de Lionel Groulx. Pierre Rajotte et Simon Benjamin tentent pour leur part de résoudre l'énigme que constitue un véritable hapax littéraire de la production québécoise. En effet, depuis sa publication en 1941, Les Voyages de Marco Polo, d'Alain Grandbois, n'a cessé d'intriguer les lecteurs et lectrices ne sachant trop comment considérer une telle auvre de réécriture qui tient à la fois de la biographie romancée, de l'essai historique et du récit de voyage. Or, le problème que pose cette œuvre-frontière ne semble peut-être pas aussi insoluble qu'on 
pourrait le croire, notamment si on la relit à l'aune de la recherche récente sur la pratique du récit de voyage. L'étiquette d'« inclassable» qu'on lui attribue généralement constitue-t-elle une solution à revoir ?

Les différents articles offrent donc l'occasion de s'interroger sur la signification d'une production qui, dans les années 1930 et 1940, déroge aux formes littéraires instituées. Si le présent numéro d'@nalyses réussit à convaincre ses lectrices et ses lecteurs de l'importance du phénomène, à baliser le terrain et à proposer des hypothèses et des pistes de lecture, il aura fait œuvre utile. Les œuvres-frontières représentent un territoire peu exploré et bien des questions demeurent sans réponse. De quoi la prolifération de telles œuvres est-elle révélatrice? Comment l'institution a-t-elle tenté de les classer et comment aujourd'hui peut-on en activer de nouvelles virtualités? Faut-il y entrevoir la manifestation d'une subjectivité émergente, l'expression originale d'une quête de renouvellement ou encore le foyer inattendu d'une certaine modernité? Alors que l'on assiste à une spécialisation disciplinaire des sciences humaines, peut-on par ailleurs voir dans les œuvres-frontières la recherche active et originale d'une autonomie littéraire? 